\title{
Globalization of nitrogen deposition and ecosystem response: A 20-year perspective
}

\author{
This article belongs to Ambio's 50th Anniversary Collection. Theme: Eutrophication
}

\author{
Sharon J. Hall, Kathleen A. Lohse, Pamela A. Matson
}

Published online: 3 February 2021

The 1990s were, in many ways, the decade that launched the analysis of environmental change at global scales. Starting in 1987, the International Geosphere-Biosphere Program (IGBP), a program of the International Council of Scientific Unions, built a broadly-based interdisciplinary, international community of scientists focused on understanding global changes in land, water, ocean, and atmospheric systems and their interactions with human systems. National research efforts in many countries of the world likewise began to focus on regional environmental changes and their global consequences. As the body of research grew, reviews and syntheses carried out by the IGBP and other international working groups focused attention on what was known while also highlighting parts of the globe and aspects of biogeophysical processes for which data were scarce and understanding was limited. The March 2002 Special Issue of Ambio, in which our paper was published, served to communicate the current knowledge of the global environmental change community on the problem of reactive nitrogen $(\mathrm{N})$, both in terms of its sources and the effects of excess in the environment. The Second International Nitrogen Conference had just convened a few months earlier in Maryland (USA), where scientists, agriculturalists, and policymakers discussed the state of science on the spatial and temporal patterns of anthropogenic $\mathrm{N}$ and impacts on air and water quality, food production, primary productivity, and biodiversity.

The scientific community had gained tremendous knowledge about anthropogenic $\mathrm{N}$ in the preceding decade. Although global in intent, most of the papers presented at the Second International Nitrogen Conference (as well as the first conference in the Netherlands a few years earlier) were focused primarily on data-rich, moderately wet ecosystems of North America and Europe, where ecological systems had acutely and visibly experienced the negative effects of chronic acid precipitation and $\mathrm{N}$ deposition for decades. While the research focus had been on the well-studied global north, the community realized that elevated rates of $\mathrm{N}$ deposition were likely occurring downwind of cities and intensively managed agricultural systems everywhere across the planet, driven by rapid urban and agricultural development. For many of these areas, there were no deposition data to characterize the magnitude of inputs to ecosystems or identify major sources. We knew even less about the ecological outcomes of $\mathrm{N}$ deposition across the wide range of soils and ecosystems from across the globe that were likely to be experiencing substantial changes to $\mathrm{N}$ cycling. Our fundamental understanding of the biotic and abiotic controls over ecosystem $\mathrm{N}$ transformations, and our knowledge of nutrient limitation of primary production across a range of soils and ecosystems, suggested that it would be unwise to assume that we could predict global impacts on the basis of the northern temperate experience.

We wrote our paper (Matson et al. 2002) as a thought piece to raise questions to the scientific community, and to say "Let's move beyond the well-studied backyards of the US and Europe and recognize that the world is rapidly developing and changing." Drawing from first principles and experimental evidence, we asked: how might ecosystems around the world with varied climate, land cover, parent materials, and anthropogenic, biotic, and geomorphological histories respond to elevated $\mathrm{N}$ inputs? Will some ecosystems be more susceptible to detrimental effects of excess $\mathrm{N}$ than others? The teams of Bridget Emmett, Nancy Rabalais, Roland Bobbink, John Aber, and Mark Fenn had published recent syntheses on the consequences of excess $\mathrm{N}$ across important temperate ecoregions of forests, heathlands, estuaries, and the coastal ocean. Thus, at the time, we did not attempt a thorough review, but 
rather we aimed to highlight likely ecosystem responses outside of these relatively well-studied systems, to "point to some of the conditions under which anthropogenic impacts can be significant, some of the factors that contribute to variations in response, and some of the areas where uncertainty is large due to limited information."

The 2002 Ambio paper struck a chord, and helped support new and ongoing activity to investigate the biogeochemical mechanisms underlying the outcomes of $\mathrm{N}$ enrichment across a range of terrestrial ecosystems. Pushing beyond the kind of exploratory analysis that we provided in the paper, however, required a number of important scientific steps. While it was well known that rates of urbanization and chemical fertilizer use were increasing rapidly in the emerging economies of Brazil, China, and India, among others, deposition networks and systematic data collection systems were non-existent at any scale in many regions and countries. Scholars in China were measuring deposition, thanks to monitoring networks that began in 1980 and intensified throughout the 1990s, but careful analyses of extent and impacts began only in the 2000s. While growth in monitoring networks continued in many places, complete gaps in air quality monitoring sites remained in other areas, frustrating many of us who worried about the unseen consequences that were impacting people and their ecosystems in developing regions. To address these insufficiencies, a number of scientific groups created models to estimate the magnitude and global distribution of $\mathrm{N}$ deposition using data and assumptions of reactive nitrogen emissions and coupling these to global atmospheric transport models. Important research by Beth Holland, Jim Galloway, Frank Dentener, and their teams led to some of the first global $\mathrm{N}$ deposition models and maps, telling a story well beyond the few regional and even fewer continental networks that were measuring air pollutants at the time. These novel estimates confirmed that post-industrial $\mathrm{N}$ deposition was heterogeneously distributed and elevated by at least fourfold in many northern hemisphere temperate systems. Additionally, this research provided significant, although coarse, context for comparative ecosystem studies on the consequences of $\mathrm{N}$ enrichment in the biosphere.

The 2000s also brought a greater focus on sources of $\mathrm{N}$ deposition, with studies in some places indicating that agricultural fertilization was the primary source of gaseous $\mathrm{N}$, unlike the situation in the eastern US and northern Europe of the 1980s and 1990s where most deposition resulted from gases released from fossil fuel burning in mobile and stationary sources. For our research team, the ongoing deposition work dovetailed with our analyses of $\mathrm{N}$ trace gas emissions from agricultural systems in tropical and subtropical areas, where, depending on management practice, fluxes of nitrous oxide (a greenhouse gas) and nitric oxide (a precursor to acid rain) were incredibly high. Ground-based research was increasing our knowledge of emissions sources-a necessity for mitigating depositionbut the consequences in terms of deposition amounts and downwind ecosystem effects often remained unclear, and in some places still do.

Without reliable data to illuminate local or regional $\mathrm{N}$ deposition gradients, the ecosystem science community turned to experimental, plot-based studies using $\mathrm{N}$ fertilizer inputs at various levels to explore the mechanisms underlying complex ecological responses. Such studies were conducted across a range of systems in Brazil, China, Panama, among other places. A few years prior to the Ambio paper, our team had explored $\mathrm{N}$ trace gas emissions and leaching losses following experimental $\mathrm{N}$ inputs across a chronosequence of ecosystem development in subtropical Hawai'i, including N-limited wet forests on pedogenically young soils (approximating, albeit imperfectly, nutrient limitation conditions of many northern ecosystems) as well as phosphorus (P)-limited forests on pedogenically old soils that we thought better approximated conditions in continental tropical and subtropical systems on highly weathered substrates. Exploring how different types of ecosystems would respond to $\mathrm{N}$ inputs, grounded in theories of ecosystem and soil development, was the motivating force behind our work in Hawai'i. There, we showed that experimental $\mathrm{N}$ additions were more likely to be lost as gases through nitrification and denitrification in P-limited forests compared to $\mathrm{N}$-limited forests where $\mathrm{N}$ was preferentially retained in soils and biomass. Additionally, $\mathrm{N}$ losses in leachate were controlled more by soil/substrate texture than the degree of $\mathrm{N}$ limitation (or saturation) of the biota. These data supported other work that showed high background rates of relative nitrification (proportion of mineralized $\mathrm{N}$ that is nitrified) in ecosystems where resources other than $\mathrm{N}$ more strongly limit primary production, like water-limited drylands, or tropical forests where plant growth is limited by $\mathrm{P}$ or base cations. In other words, some terrestrial ecosystems naturally ran on nitrate economies, not just those that were saturated by $\mathrm{N}$ deposition like northern forests.

In the nearly two decades since our paper was published, our understanding of deposition sources, amounts, and ecosystem consequences has become truly global. Perhaps equally important, we now consider the local-to-global biogeochemical consequences of deposition as part of a compounding, multiple-stressor system. Today we know that $\mathrm{N}$ inputs from deposition can only be evaluated in the context of disturbance, other nutrient inputs, and pollutant exposure, and they interact in complex ways with species and ecosystems across gradients of soils and climate. Furthermore, these complexities are shaped by the overarching impacts of a rapidly changing climate as well as 
feedbacks with social systems that drive ecological processes.

For us, as young (and sort-of young) researchers, the decade leading up to the Ambio paper was an incredibly exciting time to be in science. Hypothesizing and uncovering the dynamics of environmental changes and evaluating their consequences for the Earth system was fun-as is all such discovery, we expect. But understanding that these dynamics held serious consequences for the wellbeing of people and the whole Earth system, today and in the future, was sobering. Ultimately, this work changed the course of our research lives. By the time of the 2002 Ambio publication, we could still take considerable joy in understanding how the world works and how it is changing, but our foci had turned much more toward what to do about it. We shifted to use-inspired research for much of our work - the kind that falls in Pasteur's Quadrant (Stokes 1997) — caring both about making fundamental discoveries to advance scientific understanding as well as helping to address problems that affect the short and long-term wellbeing of people and ecosystems.

\section{REFERENCES}

Matson, P., K.A. Lohse, and S.J. Hall. 2002. The globalization of nitrogen deposition: Consequences for terrestrial ecosystems. Ambio 31: 113-119. https://doi.org/10.1579/0044-7447-31.2.113.

Stokes, D.E. 1997. Pasteur's quadrant: Basic science and technological innovation. Washington, DC: Brookings Institution Press.

Publisher's Note Springer Nature remains neutral with regard to jurisdictional claims in published maps and institutional affiliations.

\section{Sharon J. Hall ( $\square)$}

Address: School of Life Sciences, Arizona State University, Tempe, AZ 85281, USA.

e-mail: sharonjhall@asu.edu

\section{Kathleen A. Lohse}

Address: Department of Biological Sciences, Idaho State University, Pocatello, ID 83209, USA.

\section{Pamela A. Matson}

Address: Department of Earth System Science, Stanford University, Stanford, CA 94305, USA. 